\title{
Numerical Product Design: Springback Prediction, Compensation and Optimization
}

\author{
T. Meinders ${ }^{\text {a }}$,I.A. Burchitz ${ }^{\text {a,b }}$, M.H.A. Bonte ${ }^{\mathrm{a}}$, R.A. Lingbeek ${ }^{\mathrm{a}, \mathrm{b}, \mathrm{c}}$ \\ ${ }^{a}$ University of Twente, P.O.Box 217, 7500AE Enschede, The Netherlands \\ b Netherlands Institute for Metals Research, P.O.Box 5008, 2600GA Delft, The Netherlands \\ ${ }^{\mathrm{c}}$ Inpro Innovationsgesellschaft fur fortgeschrittene Produktionsysteme in der Fahrzeugindustrie, Hallerstrasse 1, D-10587 \\ Berlin, Germany
}

\begin{abstract}
Numerical simulations are being deployed widely for product design. However, the accuracy of the numerical tools is not yet always sufficiently accurate and reliable. This article focuses on the current state and recent developments in different stages of product design: springback prediction, springback compensation and optimization by Finite Element (FE) Analysis. To improve the springback prediction by FE Analyis, guidelines regarding the mesh discretization are provided and a new through-thickness integration scheme for shell elements is launched. In the next stage of virtual product design the product is compensated for springback. Currently, deformations due to springback are manually compensated in the industry. Here, a procedure to automatically compensate the tool geometry, including the CAD description, is presented and it is successfully applied to an industrial automotive part. The last stage in virtual product design comprises optimization. This article presents an optimization scheme which is capable of designing optimal and robust metal forming processes efficiently.
\end{abstract}

Key words: springback, compensation, optimization, metal forming

\section{Introduction}

Sheet metal forming is a widely used production process, e.g. in the automotive industry (outer panels, inner panels, stiffeners), the packaging industry (pet food containers, beverage cans) and the household appliances industry (housings, razor caps). Although most sheet metal forming processes have been successfully applied for decades, the entire process is still not fully understood. As a result, a costly and time consuming trial and error process must be started to determine the proper process design, leading to the desired product. The lack of understanding is becoming even more pronounced, since

Email address: v.t.meinders@ctw.utwente.nl (T. Meinders). industries tend to favor light construction principles, leading to the usage of new materials and new production processes like hydroforming and incremental forming.

Presently, Finite Element (FE) Analyses are used to enhance the understanding of sheet metal forming processes. Although FE Programs are quite sophisticated nowadays, their accuracy and reliability do not yet satisfy the industrial requirements. Amongst others, some of the main reasons are the inaccuracy of the used numerical algorithms (e.g. numerical integration, element formulation) and lack of experience in using the FE Code. As a result, the FE Method is not sufficiently capable of simulating forming processes and subsequently unable to accurately predict the springback behavior. Therefore, research in these fields is necessary to improve 
the usability of numerical simulations in sheet metal forming. This article focuses on numerics in relation to springback prediction, as explained in Section 2. Various simplifications, introduced for making a simulation of forming more efficient, may have a significant influence on the accuracy of springback prediction and are reanalyzed in this article. Besides, a new integration algorithm is developed to improve the accuracy of a springback analysis at minimal costs.

Springback is a major problem for processplanning engineers. In many cases the shape deviation of the sprung back part and the desired product is so large that springback compensation is needed. The tools of the sheet forming process must be changed such that the product becomes geometrically accurate after springback. In industrial practice, deformations due to springback are compensated manually by doing extensive measurements on prototype parts, and altering the tool geometry by hand, which is a time consuming process. The FE Method can be used for springback compensation. In this article a procedure is described to automatically compensate the CAD tool shape to obtain the desired product shape (Section 3). The potential of this method is successfully demonstrated by an industrial automotive part.

The final step in virtual product design is optimization. Cost saving and product improvement have always been important goals in the metal forming industry. To achieve these goals, metal forming processes need to be optimized. Until recently, trial-and-error methods were used in factories for process optimization. Nowadays, numerical simulations, and the possibility of coupling these numerical simulations to mathematical optimization algorithms, are offering a promising alternative to design optimal metal forming processes instead of only feasible ones, as explained in Section 4. An overview of possible optimization algorithms that can be applied to optimize metal forming processes using time-consuming FE simulations will be given. A promising optimization strategy that assists an engineer to efficiently model an optimization procedure is proposed. It includes an efficient problem solving algorithm and addresses a future trend in metal forming simulation: optimization of robust metal forming processes.

\section{Springback Prediction}

Springback may be defined as an elasticallydriven change of shape of a product which occurs when external loads are removed. In many cases the shape deviation of the sprung back part and the desired product is so large that springback compensation is needed to obtain the desired product. In virtual product design, this compensation will be based on the springback prediction provided by an FE Analysis. An efficient springback compensation therefore requires an accurate springback prediction. Various experimental procedures used to study springback revealed that it is a complex physical phenomenon which involves small scale plasticity effects and thus, depends on a deformation path, crystallographic texture and its evolution [1]. Therefore, to accurately model the phenomenon in FE Analysis it is preferable to use physically-based material models, which are fully capable of describing complex material behavior such as the Bauschinger effect and inelastic effects during unloading.

Accuracy of the prediction of springback is also influenced by factors that are responsible for quality of simulation of a forming step. In the past decades, various assumptions were introduced to make forming simulations more efficient at the cost of accuracy. Applicability of most of the assumptions to the springback analysis should be reanalyzed. For example, some studies indicate that simplification of loading and unloading conditions [2,3] and assumptions underlying a shell elements theory [4] may be contrary to reality and are not applicable to the springback analysis. Spatial discretization introduces another approximation and it is recommended that finer meshes and more integration points in thickness direction are needed for an accurate springback simulation $[4,5]$.

Some results of a numerical study, which was performed to develop guidelines on a level of blank discretization in a springback analysis of real industrial components, are discussed in Section 2.1. An adaptive through-thickness integration strategy for shell elements is presented in Section 2.2, which may help to improve springback prediction accuracy at minimal costs.

\subsection{Mesh Density in Springback Analysis}

The theory of FE Analysis suggests that to reduce an error due to discretization, sufficiently fine 
meshes must be used in places of high stress gradients. In sheet metal forming high stress gradients appear in regions of abrupt changes of geometry, for example at the tool radius. It is often recommended in literature, that accurate springback analysis requires a blank to be discretized so that an element which is in contact with the tool radius covers $5^{\circ}-10^{\circ}$ of turning angle. An angle of $5^{\circ}$ per element places high CPU power demands and is not desirable in simulations of industrial components. To define the level of blank discretization that can help to establish a balance between efficiency and accuracy of springback analysis, a numerical study is performed which is based on a test of bending of a beam under tension.

In the test a strip specimen is bent over a tool radius $(R=10 \mathrm{~mm})$ and during bending a constant value of tension is applied. A number of simulations is performed with the inhouse FE Code DiekA with a blank discretized using Discrete Kirchhoff triangular elements with 7 integration points through the thickness. A dual phase steel DP965 with a Young's modulus of $205 \mathrm{GPa}$, a Poisson ratio of 0.3 and a yield stress of $650 \mathrm{MPa}$ is used in the analysis.

A value of internal bending moment is used to quantify springback. The bending moment obtained from a simulation with the finest mesh is chosen to be a reference. A relative difference between the reference bending moment and a moment calculated from the simulations with other mesh densities gives a relative moment error. Hence, the springback error induced by the discretization error is proportional to this relative moment error.

Figure 1 shows results of simulations in which the relative moment error is plotted versus the number of elements that are in contact with the tool radius. The tension is equal to 0.1 times the tension needed to initiate material yielding.

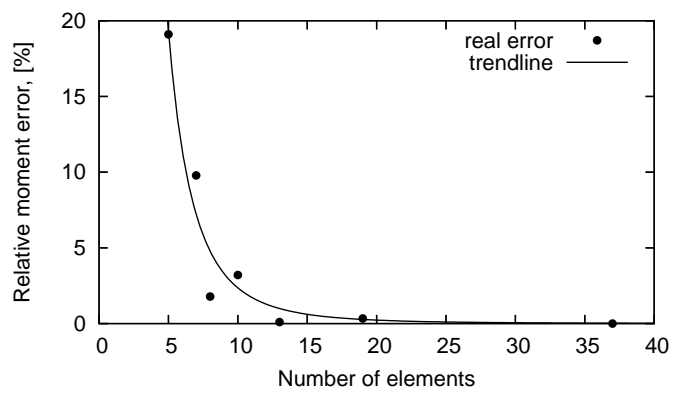

Fig. 1. Variation of the relative moment error depending on mesh density.
The figure shows that to have an accuracy of about $1 \%$ in this springback analysis it is necessary to minimize the discretization error by using about 10 elements over the tool radius, an angle of $9^{\circ}$ per element. Simulations with other materials under the same process conditions lead to similar results and hence not presented here.

A top-hat section test is used to check the inference, mentioned above. The test resembles the NUMISHEET'93 benchmark [6] except for the tools' radii. A number of simulations is performed in which blanks with various mesh densities are used. Results of the simulations with aluminum alloy (Young's modulus of $71 \mathrm{GPa}$, a Poisson ratio of 0.34 and an initial yield stress of $125 \mathrm{MPa}$ ) are reported in Figure 2, where a shape of the blank after unloading is shown. Starting from $9^{\circ}$ per element around the tool radius (the curve with 10 elements) the final shape does not differ significantly, verifying the rule that a discretization density of 10 elements over a tool radius gives accurate results.

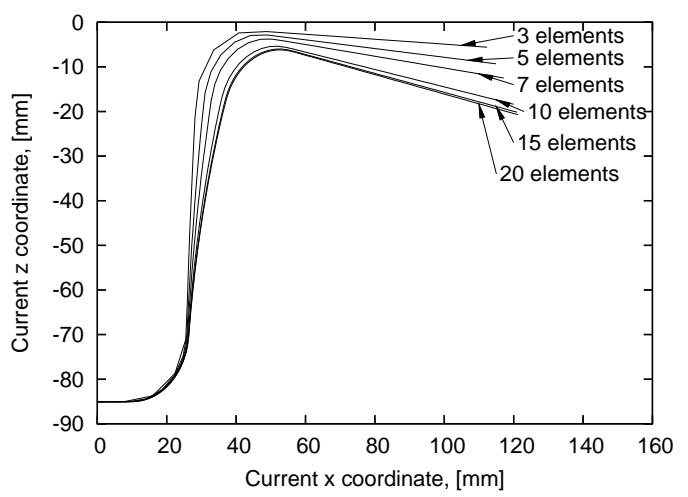

Fig. 2. Top-hat section test. Shape after springback.

However, note that the conclusions presented here are applicable to situations when Kirchhoff elements are used for the blank discretization. It is likely that fewer higher-order elements are required to achieve similar accuracy of the springback prediction. In practice, it is beneficial to employ an adaptive mesh refinement procedure that includes a type of posteriori error estimate which will trigger mesh revision in the regions with high stress gradients.

\subsection{Advanced Integration Scheme for Shell Elements}

In FE Analysis characteristic matrices of elements are complex volume integrals that are solved 
by numerical integration. In shell elements this integration is split into an in-plane integration and a through-thickness integration. In this article the focus is on the latter.

Standard integration rules are available to perform the through- thickness integration, e.g. Trapezoidal integration. To describe bending effects, usually more than one integration point in the thickness direction is needed. When a material undergoes plastic deformations there appear points of discontinuity in through-thickness stress profile. None of the standard rules can guarantee accurate results in this case and the number of the integration points required to represent the non-linear stress profile increases [7]. It was shown that depending on a material, process parameters and the integration rule, $10-50$ integration points are needed through the thickness to minimize influence of numerical integration error on springback prediction [8]. Very likely, the reason for this is the inability of the integration schemes to accurately cope with discontinuities. Such a broad range of the required integration points shows inefficiency of the standard integration rules. Furthermore, using more than 20 integration points places high demands on computational power and is very undesirable.

To overcome this problem one may use a strategy that is based on adaptive integration. An integration rule of the strategy may change its definition and placement of the integration points to adapt itself to a varying stress profile. Ideally, integration points will be placed in the locations where the discontinuities appear, which assure that these discontinuities do not influence the accuracy. Thus a number of the integration points needed to guarantee a certain level of accuracy of springback prediction may be reduced significantly.

A flexible framework for constructing algorithms for adaptive integration is suggested by Rice [9]. Using the framework, an adaptive noniterative integration strategy for shell elements is defined. It consists of two groups of components: an interval manager and an interval processor. The components are described in Figure 3.

The first task of the interval manager is to locate points of discontinuity in the integrand profile. Several points of discontinuity may be present in a stress profile when a material undergoes cyclic bending and unbending while passing, for example, a die radius. Figure 4 shows a fictive through-thickness stress profile which occurs in a beam after bending and reverse bending without tension. Elastic, per-

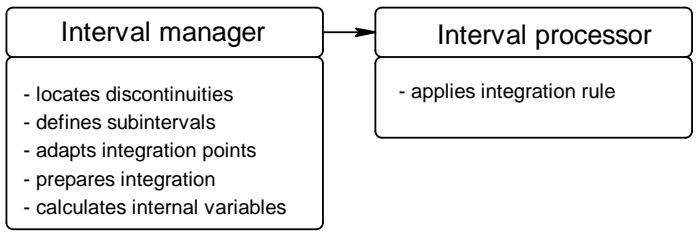

Fig. 3. Schematic of adaptive through-thickness integration algorithm for shell elements.

fectly plastic material is chosen and, due to a symmetry, only half of the stress profiles is shown.

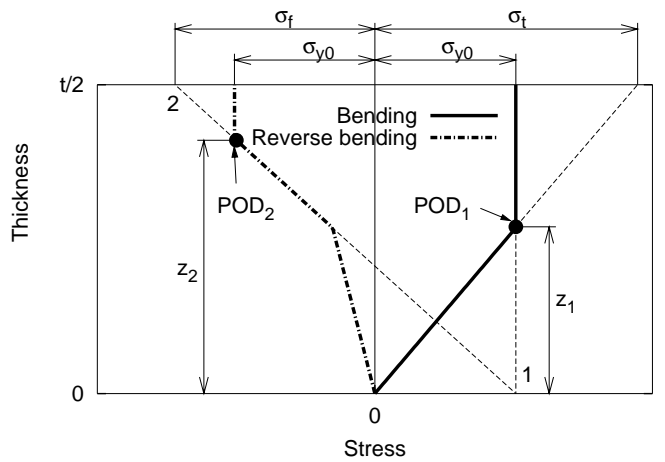

Fig. 4. Through-thickness stress profiles for bending/reverse bending.

While bending, as soon as yielding of the material is initiated, an elastic-plastic boundary or a point of discontinuity (POD1 in Figure 4) appears in the stress profile. $\sigma_{y 0}$ is the initial yield stress and $\sigma_{t}$ is the trial stress. Yielding of the material during loading in the reverse direction produces a new elasticplastic boundary and a new point of discontinuity (POD2). $\sigma_{f}$ is a fictitious elastic stress that would exist if the material did not become plastic during the reverse loading. It can be shown that a slope of the fictitious elastic stress (line $1-2$ in Figure 4) intersects the neutral axis at the location of the yield stress during the bending part of the cycle. After some work, the position of the transition points $z_{1}$ and $z_{2}$ can be calculated [10].

Following similar considerations and assuming linear stress variation in the region of plastic deformations, it is possible to define equations for locating the points of discontinuity after bending and reverse bending for an elastic-plastic material with hardening. Generalization from the considered uniaxial case to a multiaxial problem is done in [10].

Having found the location of discontinuities in the stress profile the interval manager divides the complete integration interval $\left[-\frac{t}{2}, \frac{t}{2}\right]$ into several parts. After the subdivision the discontinuities coincide 
with endpoints of the subintervals and the integrand on every subinterval is a smooth function. Integration points are rearranged so that there are several points inside every subinterval and two of the points are lying on its limits. If required, the location and number of the integration points on each subinterval can be adapted depending on used numerical integration scheme and smoothness of the integrand. Applying an integration rule to every subinterval and adding results gives a numerical value of the integral.

For high flexibility, the interval processor may employ numerical schemes that can perform integration using unequally distributed points [11]. Implementation of the adaptive through-thickness integration strategy for real material behavior requires extra attention. As soon as an integration point is relocated or newly introduced, there is no history information available for this point. Therefore, it is necessary to calculate new values of internal variables, such as stress and strain vectors and hardening parameters. These values can be calculated by interpolation using the information of old integration points. If unloading occurs, the adapted integration points will guarantee more accurate stress resultants and, therefore, more accurate change of shape.

To test the performance of the adaptive integration strategy, a moment $M$ resulting from bending of a beam to a radius under in-plane tension $T$ is calculated. A model of bending under tension is schematically represented in Figure 5. Simplicity of the model allows finding a closed form solution for the bending moment. Details of the analytical calculation of the bending moment are presented in literature, for example in [8].

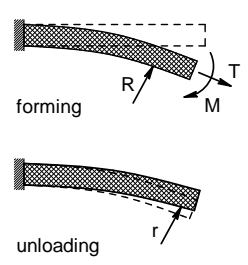

(a)

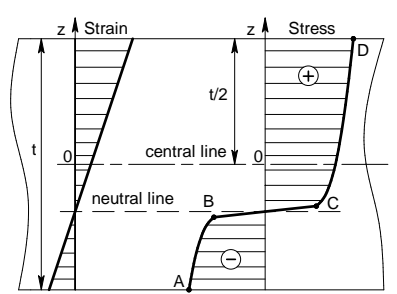

(b)
Fig. 5. (a): Deformation of a beam under combined influence of moment and tension. (b): Typical through-thickness strain and stress profiles.

Calculations are performed for a range of values of the in-plane tension. Prior to integration the interval manager of the adaptive integration strategy evaluates the integrand and performs the following tasks: (i) identifies location of two points of discontinuity (POD1) in the stress profile (symmetry);

(ii) divides integration interval $\left[-\frac{t}{2}, \frac{t}{2}\right]$ into three subintervals $A B, B C$ and $C D$, shown in Figure 5;

(iii) adapts location of the integration points on every subinterval.

For integration on every subinterval, the interval processor employs a rule that uses a natural cubic spline to approximate the integrand.

To show the performance of the traditional integration schemes the trapezoidal rule is used to calculate the bending moment. A value of the in-plane tension that causes a neutral line shift of $-0.4 \mathrm{~mm}$ is chosen. A set of calculations is performed with a varying number of integration points. An error due to applying the numerical integration is quantified by finding a relative difference between values of the bending moment calculated analytically and numerically. Figure 6 shows the relative moment error plotted versus the number of integration points. Presence of points of discontinuity in the stress profile leads to a considerably high error when using less than 10 integration points.

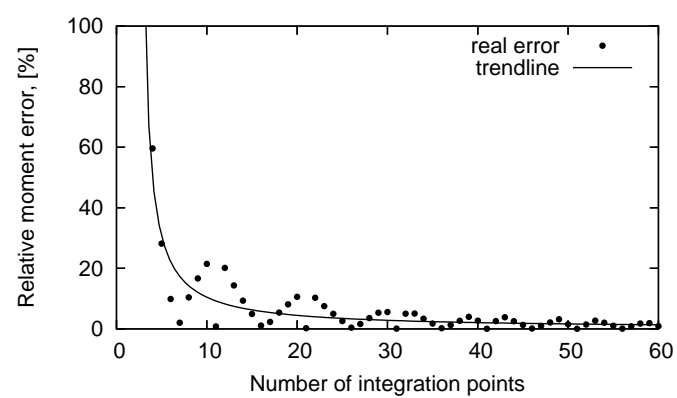

Fig. 6. Relative moment error due to integration with trapezoidal rule.

Results of numerical integration with a fixed number of the integration points are shown in Figure 7, where the relative moment error varies as a function of the in-plane tension. In this figure, the inplane tension is represented by the normalized shift of the neutral line. The numerical integration is performed using the trapezoidal rule with 50 integration points and the adaptive spline integration with only 11 points.

The integration error, obtained when using the trapezoidal rule, oscillates. It occurs because for different in-plane tension the location of the points of discontinuity in the stress profile vary to the location of the integration points; the closer the locations are, the smaller the error [8]. This fact makes 


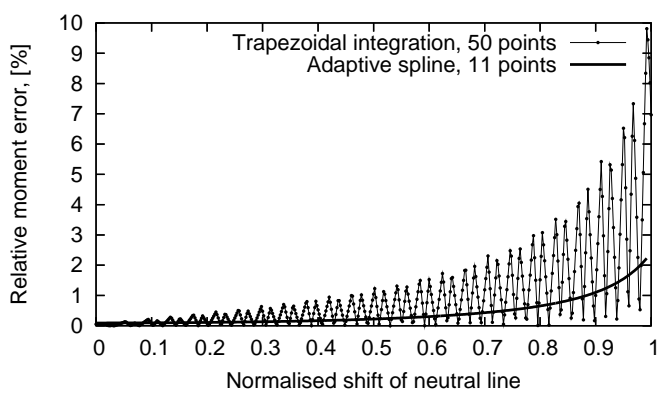

Fig. 7. Relative moment error for various values of in-plane tension obtained with traditional trapezoidal rule and adaptive spline integration.

it very difficult to develop practical guidelines for selection of the number of integration points. Slight variation of process parameters, the in-plane tension in this case, may lead to a very high or very low error for the same number of points. At the same time, advantages of using the adaptive integration strategy are clearly seen. The adaptive spline integration helps to obtain a very low error using a small number of the integration points. Additionally, tracing the location of the points of discontinuity in the stress profile removes the error oscillation. Therefore it becomes possible to guarantee some level of the error which can occur when using a specific number of the integration points.

\section{Springback Compensation}

Applying the methodology described so far will provide an improved accuracy of springback prediction. Then, the FE Method results can be used in the next step of virtual product design: account for product shape deviations after springback. The first step towards a geometrically accurate product is to reduce springback as much as possible, for example by optimizing the blankholder load. However, some springback will always be present. When the geometrical tolerances are exceeded or when, in the case of products with a low stiffness, the forces required to push the part back into the right shape are exceeded, springback compensation is required. This means that the surfaces of the forming tools are modified in such a way that the shape of the formed product is accurate after springback. Recently, there has been a lot of attention for springback compensation [12]. The Displacement Adjustment (DA) method [13-15] has been proven to be the most successful.
The principle behind the DA method is simple. When the product springs back in a certain direction, the tool surface is displaced into the opposite direction. Generally, springback increases when the tool surfaces are compensated, so to take this into account, the tools have to be over-compensated. For this, the overbending-factor $\mathbf{a}$ is used. This principle is captured in Equation 1. D is the desired (reference) product geometry, represented as a set of points or a FE mesh. This geometry is used to create a deep drawing tool-set. A FE simulation is carried out which provides $\mathbf{S}$, the geometry after springback. The compensated geometry $\mathbf{C}$ is calculated as follows:

$$
\mathbf{C}=\mathbf{D}-\mathbf{a}(\mathbf{S}-\mathbf{D})
$$

The compensation factor is different for each product and can be as large as 2.5 [16] and it cannot be predicted effectively. However, in Section 3.1 some trends are shown for various process, material and geometrical parameters.

The use of a compensation factor is avoided when the DA method is carried out iteratively, as proposed in [13]:

$$
\mathbf{C}^{j+1}=\mathbf{C}^{j}-\left(\mathbf{S}^{j}-\mathbf{D}\right)
$$

Here, the first compensated geometry is called $\mathbf{C}^{1}$, and with this geometry a new FE simulation is started. The resulting springback mesh $\mathbf{S}^{1}$ is now used to modify $\mathbf{C}^{1}$, delivering the second compensated geometry $\mathbf{C}^{2}$. This loop is continued until the shape deviation of $\mathbf{S}^{t}$ meets the tolerances.

In Equations 1 and 2 the geometries $\mathbf{D}, \mathbf{S}$ and C need to be topologically identical. Therefore, the tool geometry needs to be reconstructed from $\mathbf{C}$ after each iteration. The surface of the compensated geometry may become rougher with each iteration, which causes problems for the forming process. These problems are solved in an extended version of the DA algorithm called Smooth DA or SDA [17]. Instead of using the shape deviation field between springback and desired geometry directly, it is approximated with a smooth mathematical function, Section 3.2. Finally, the compensation needs to be transferred from the FE simulation to the tool CAD files. This is discussed in Section 3.3.

\subsection{Analytical Model}

In the stretch-bending process [8], shown in Figure 5 , an initially straight bar is bent to a certain radius $R$ under the action of a moment $M$ and at the same time it is loaded with a stretching force 
$T$. After forming, the bar is unloaded and it springs back into a shape with a radius of $r$. In a real deep drawing process, increasing the tensile stress by increasing the blankholder load causes a reduction in springback. The same phenomenon occurs for the stretch-bending model. Here, all deformations can be calculated using analytical formulas instead of FE simulations, which makes the model well-suited to analyze the results of springback compensation.

Springback compensation means that in case of the stretch-bending model, the forming radius $R$ is estimated, resulting in a desired bar radius after springback, $r$. Because $R$ and $r$ are related by a (nonlinear) function, the optimal value of $R$ can be calculated directly, without applying a compensation algorithm [16]. With this optimal forming radius, the overbending factor which would have been required to obtain the same results with the DA method, can be calculated. The results are shown for various tensile forces and for two different materials, low strength Interstitial-Free steel and high strength DP600 steel (Figure 8). In order to simplify the comparison, the tensile force was normalized with the force required to achieve plastic deformation under tension only.

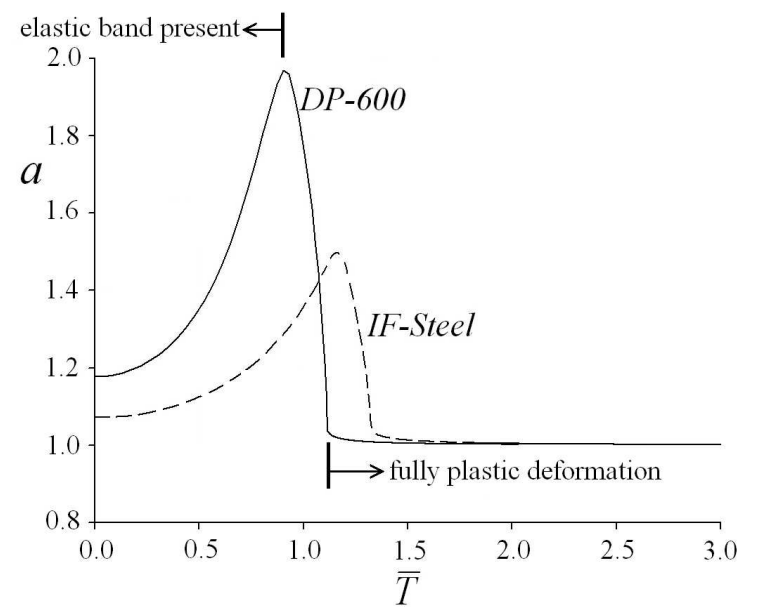

Fig. 8. Optimal compensation factor for two different steels at varying tensile force, $R / t=100$.

The figure shows that for different tensile forces, different compensation factors are required. Two situations can be identified:

- when the tensile force is relatively low, both elastic and plastic bands are present in the bar. Due to shifting of the neutral line, springback increases considerably when the bar is bent further for compensation. This means that over- compensation has to be applied, and the value of the compensation factor is larger than 1.0;

- when the tensile force is large enough to cause the elastic band to disappear (region $B C$ in Figure 5 does not exist anymore), the bar is completely plastically deformed. When the bar is deformed further for springback compensation, the amount of springback hardly changes. Therefore, no overcompensation is required and a factor of 1.0 can be used.

In a real product, different tensile stresses occur at different places, and only at local spots the forming stresses are so large that the blank is deformed in the plastic region only, whereas the rest of the product still has an elastic band through the thickness of the blank. This means that the compensation factor has to be different at different locations in the product. This is only the case for iterative compensation, which will be discussed in more detail in Section 3.2.

Another important factor is the geometry of the tools and the product. In the stretch-bending model, this influence can be shown by altering the value of $r_{\text {target }} / t$, where $t$ is the thickness of the bar. For large values the model resembles a shallowly curved geometry, like a body panel. For small values details with sharper edges are modeled. Figure 9 shows that the larger the radius, the smaller the compensation factor [16]. As real deep drawn products generally have very complex shapes, this shows again that the compensation factor needs to be different at different locations in the product.

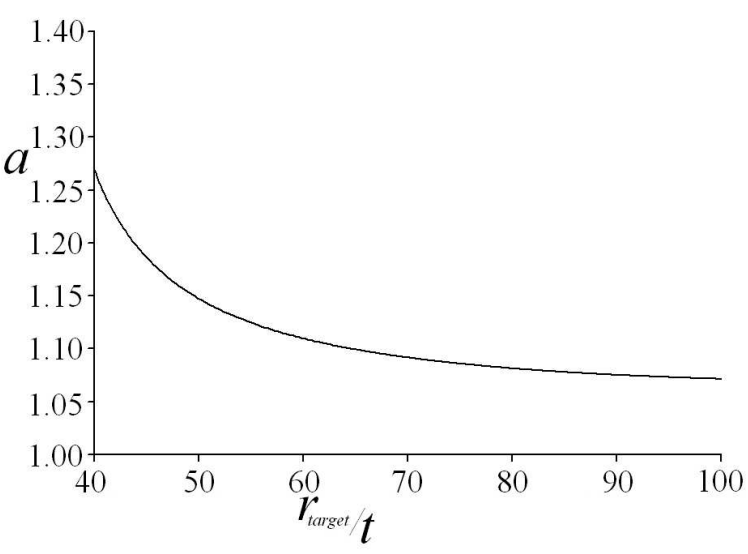

Fig. 9. Optimal compensation factor vs. target radius. $t=0.01$, IF-Steel 


\subsection{Industrial Application}

With the SDA algorithm, it is possible to carry out springback compensation on real products and create a new tool-set that not only delivers accurate products, but that also meets practical requirements $[16,17]$ :

- the smoothness of the tool surfaces is retained;

- the gap-width between the tool surfaces remains the same;

- compensation can be carried out such that the blankholder remains unchanged;

- undercuts in the compensated tools can be avoided or automatically repaired.

A deep drawn product by DAF is compensated here, based on simulations with the commercial code PAM-STAMP 2G. It is made from mild steel with a thickness of $2 \mathrm{~mm}$ and produced in a complex process, including three forming stages and two trimming stages. Figure 10(a) shows that the product was already rather accurate with the original tools. Note that the bumper is symmetric, so only half of the geometry is simulated. The relative geometrical error is calculated using the maximum initial error. The results of the first iteration (middle) show that even though the shape deviation of a major portion of the product is small, a large error is still present in the middle of the bumper. After 5 iterations (c), the maximum shape deviation was reduced below the tolerance throughout the part.
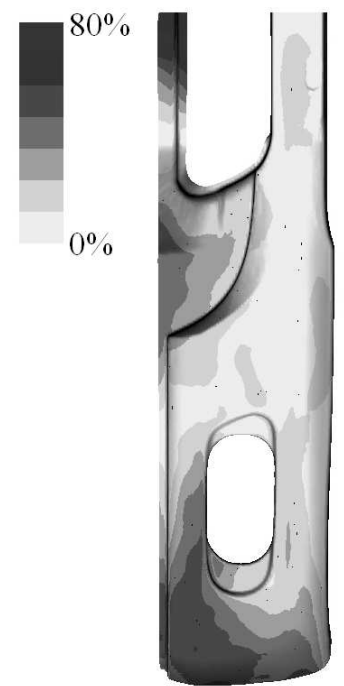

(a)

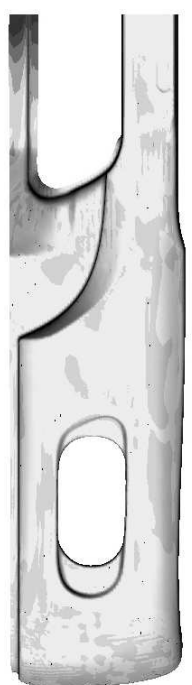

(b)

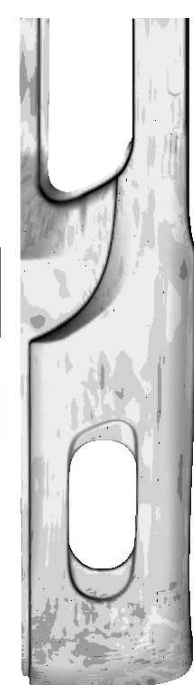

(c)
Fig. 10. Shape deviation of the DAF part with initial tools (a), after the first iteration (b) and after 5 iterations (c).
When the original springback shape deviation, and the compensated geometry are compared, a local compensation factor can be derived. Figure 11 shows this value, and as discussed in the previous section, the compensation factor varies heavily over the product. Following the conclusions from Figure 9 , the more shallowly curved areas have a much lower compensation factor.

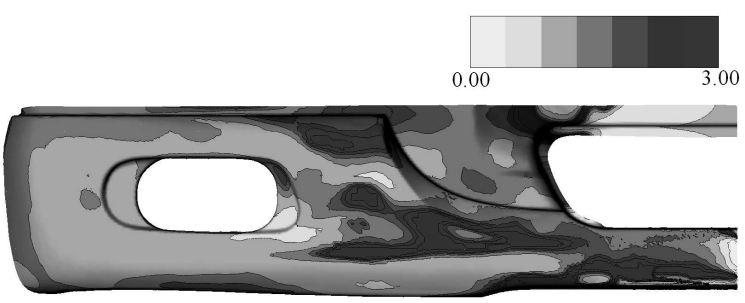

Fig. 11. Local overbending factor on the DAF part.

This increase in dimensional quality is confirmed when the results of the one-step compensation are compared with the iterative results. From the values in Figure 11, a (weighted) mean compensation factor of 1.2 was calculated, which is used as compensation factor in the one-step compensation approach.

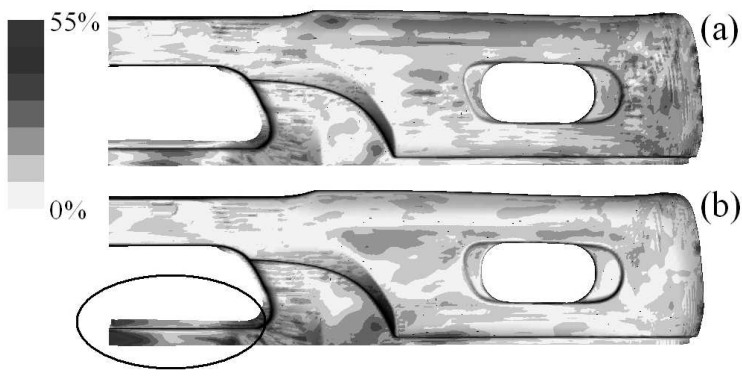

Fig. 12. Iterative (a) and one-step (b) compensation.

The resulting shape deviation is depicted in Figure 12. Although the one-step compensation leads to a low shape deviation in a major portion of the product, the tolerances were exceeded by about $150 \%$ in the area indicated in the figure, whereas the iteratively compensated product met the requirements completely. It should be kept in mind that normally, there is no way to calculate the compensation factor in advance, so it is very likely that 5 experiments would be required to obtain good results. 


\subsection{Automatic Adaptation of CAD Tool Geometries}

As a final step in the compensation process, the CAD data of the tools needs to be adjusted. The CAD geometry needs to be very smooth in order to produce acceptable (car body) parts.

These geometries are also referred to as 'ClassA' geometries. The narrow tolerances are required because of light reflections on the painted surface. A body panel will appear smooth when both the curvature and the change in curvature are smooth. Errors are made visible by projecting a striped light pattern onto the surface (highlighting), both with real lights and in computer algorithms. In case of a discontinuity in curvature, the stripes will be slightly offset (shown in Figure 13(b)), when a discontinuity in the second derivative is present, the stripes will be at a slight angle.

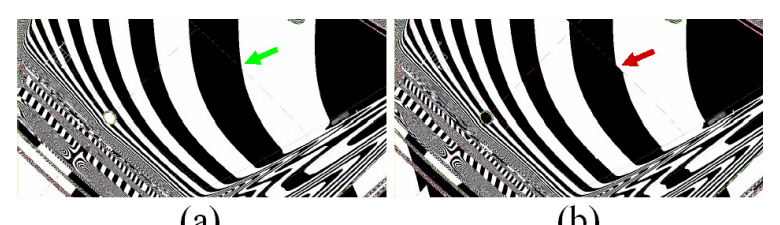

(a)

(b)

Fig. 13. Highlighting indicate a surface quality error.

Class-A parts are generally not entirely smooth; the designers make use of the visual effects of discontinuities in the surface geometry to create 'feature lines' on the body panels. Therefore, the surfaces are connected with complex boundary conditions that need to be retained during compensation. This makes manual modification of CAD surfaces problematic, as either the quality of the surfaces is decreased, or the detailed modification proposed by the compensation algorithm is not achieved.

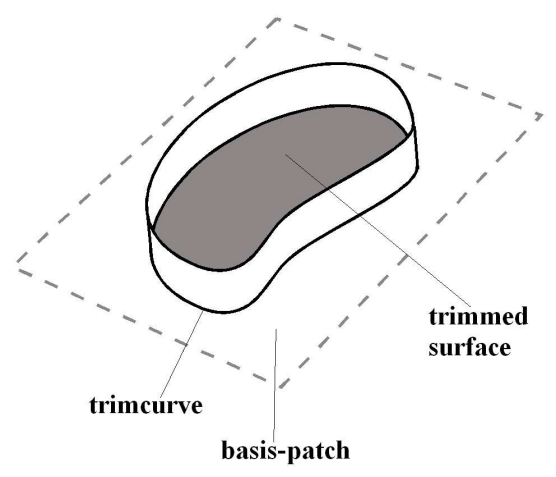

Fig. 14. A trimmed surface.

This problem is further aggravated by the frequent use of trimmed surfaces [18]. In some cases it is inconvenient or impossible to model a geometry with the four-sided Bezier or B-spline surfaces that are used in CAD programs. Such a geometry is visualized in Figure 14. The flat bottom of the cup is created as a four sided surface first, and then the unwanted parts are trimmed off to make the surface fit to the sidewalls. The four sided surface is known as the basis-patch $P$. It shall be clear that when the shape of the cup is modified globally, it becomes very hard to maintain even geometric continuity and gaps will appear between the sidewalls and the trimmed surface. In fact, small gaps are already present in the unchanged geometry: all CAD systems allow (small) tolerances for these kinds of transitions as they are generally not completely smooth from a mathematical point of view.
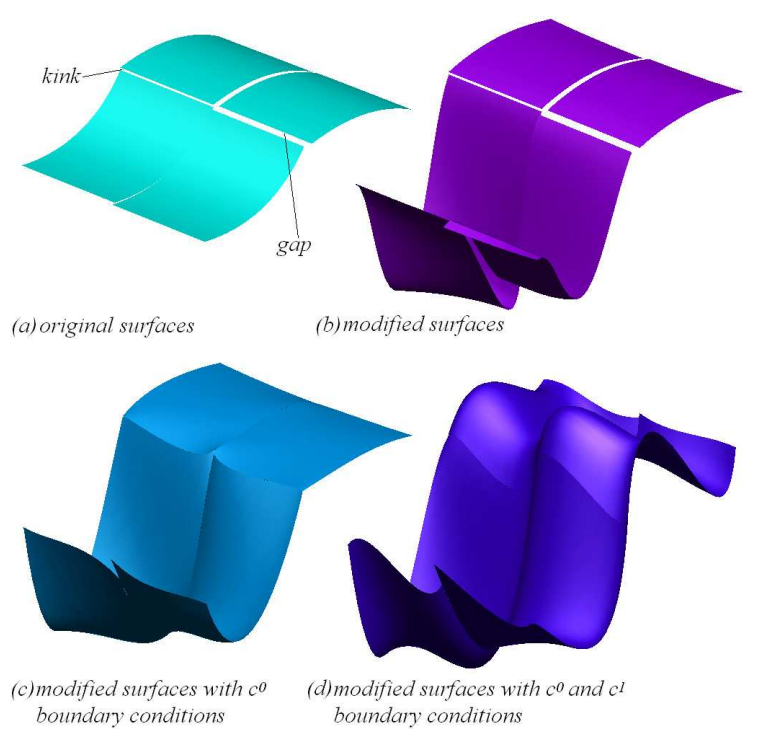

Fig. 15. Modification of a set of 4 surfaces.

An algorithm was developed to modify a CAD geometry automatically [18]. Onto the original geometry, a set of so-called sampling-points is projected. These points are modified, using the springback compensation algorithm, and then the surfaces are fitted through the modified sampling points again. Additional features are:

- boundary conditions can be applied between regular and trimmed surfaces, in any combination, up to the second derivative;

- the boundary conditions are solved using the penalty method. This means that in all cases, a modified geometry can be calculated. The accuracy of retaining the boundary condition can be set by the user; 
- The surfaces may suffer from geometrical errors in the original geometry.

As an example, in Figure 15, a set of four surfaces with kinks and gaps (a) is modified without boundary conditions (b). Then, the same modification is carried out, with boundary conditions, closing the gaps(c) or even smoothing the kinks (d). This example shows that the principle works, and it shows that imposing more boundary conditions means that the geometry may develop unwanted bulges when the surfaces have a low number of control points. In order to modify industrial CAD geometries, some more detailed tests need to be carried out.

\section{Optimization}

The previous section showed that springback compensation is an important stage in virtual product design. When thinking in optimization terminology, springback compensation can be considered as a form of process optimization. However, optimization techniques can be applied in a wider field then only springback compensation. Until recently, the FE Method was used for designing feasible production processes. Recently, coupling the FE Method to mathematical optimization techniques is evolving to address two industrial needs, i.e. (i) Designing optimal metal forming processes instead of only feasible ones (better products, lower costs); and (ii) Solving problems in manufacturing.

The basic concept of mathematical optimization is presented in Figure 16. Basically, it consists of two major phases: the modeling and the solving of the optimization problem. The modeling phase consists of three items. One item is selecting a number of design variables the user is allowed to adapt. Another item consists of choosing an objective function (the optimization aim) and the third item is to account for possible constraints.

These three items are closely related to each other as depicted in Figure 16. Both the objective function and the constraints should be quantified by the design variables. The objective function and constraints are also related to each other in the sense that they are often exchangeable.

Next to the modeling phase, mathematical optimization's second phase is solving the optimization problem. This comprises applying an optimization algorithm to the modeled optimization problem. The arrows between the modeling and the solv- ing parts in Figure 16 denote that both phases cannot be seen separately from each other. One should select the right optimization algorithm for a certain modeled optimization problem and one should model the optimization problem cleverly to adjust it to the optimization algorithm one is planning to apply. If the optimization model does not match the algorithm, it is likely that the optimization problem is not solved efficiently or cannot be solved at all [19].

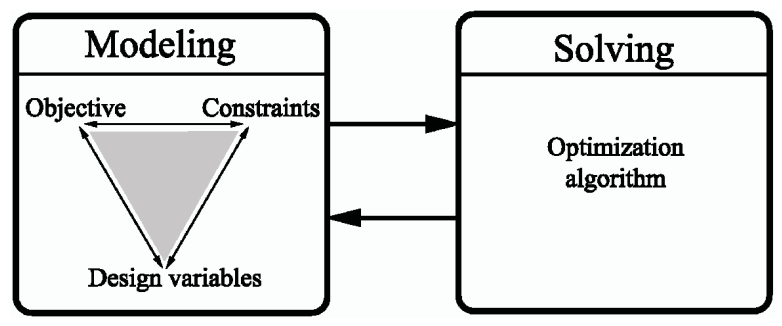

Fig. 16. The basic concept of mathematical optimization: modeling and solving.

The next section reviews the research performed in the field "Optimization of metal forming processes using time-consuming FE simulations". In Section 4.2 an optimization strategy for metal forming processes is proposed, which is applied to a hydroforming example in Section 4.3.

\subsection{Literature review}

Academic research in the field of optimization of metal forming using time consuming FE simulations has been going on now for several years, yielding a large number of scientific publications. In general, many metal forming processes are considered: deep drawing [20-43], hydroforming [44-57], superplastic forming [58-60], extrusion [61,62], forging [63-73], as well as several other processes [74-78].

Most research performed until now has been related to the solving part of optimization, i.e. the selection and application of a suitable optimization algorithm. In the remainder of this section, four major groups of algorithms are reviewed that can be applied for optimizing metal forming processes using FE simulations:

- iterative algorithms;

- evolutionary and genetic algorithms;

- approximate optimization algorithms;

- adaptive optimization algorithms.

One way of optimizing metal forming processes is using classical iterative optimization algorithms 
(Conjugate gradient, BFGS, etc. ). Using these iterative algorithms, there is a direct coupling between the FE software and the optimization algorithm as depicted in Figure 17(a): each function evaluation of the algorithm means running a FE calculation. In case of metal forming these FE calculations can be extremely time consuming and need to be sequentially evaluated. Furthermore, many classical algorithms require sensitivities, the efficient calculation of which is not straightforward for FE simulations. A third difficulty concerning iterative algorithms is the risk to be trapped in local optima. Advantages of this group of algorithms comprise the fact that they are well-known and widely spread. Additionally, convergence to a local optimum generally requires relatively few iterations and is hence fairly efficient. Especially due to the former advantage, iterative algorithms are quite often applied to optimize metal forming processes, see [20-29,44-49,58,61-64].

A second group of algorithms for which there is a direct coupling between the algorithm and the FE software (Figure 17(a)) is genetic and evolutionary optimization algorithms. Genetic and evolutionary algorithms look promising because of their tendency to find the global optimum and the possibility for parallel computing. Furthermore, they do not require the difficult calculation of sensitivities. However, the rather large number of function evaluations that is expected to be necessary using these algorithms is regarded as a serious drawback [79]. Several authors have applied genetic and evolutionary algorithms to optimize metal forming processes [43,56,57,67-73].

A third way of optimization in combination with time consuming function evaluations is using approximate optimization algorithms, of which Response Surface Methodology (RSM) is a well-known representative. RSM is based on fitting a low order polynomial metamodel through response points, which are obtained by running FE calculations for carefully chosen design variable settings and finally optimizing this metamodel [80]. Hence, for approximate optimization, the direct coupling between the optimization algorithm and the FE calculations is removed and a metamodel is placed in between as a buffer. This is schematically presented in Figure 17(b). Metamodels are sometimes also referred to as Response Surface models or surrogate models. Next to RSM, other metamodeling techniques are Kriging (or Design and Analysis of Computer Experiments (DACE)) and Neural Networks. Allowing for parallel computing and lacking the necessity for sensitiv- ities, RSM is appealing to many authors in the field of metal forming, see [30-40,65,66,75-77,81,82] Disadvantages include an approximate optimum as a result rather than the real global optimum, and the curse of dimensionality: these algorithms tend to become very time consuming if many design variables are present.

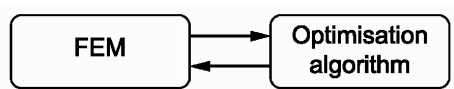

(a)

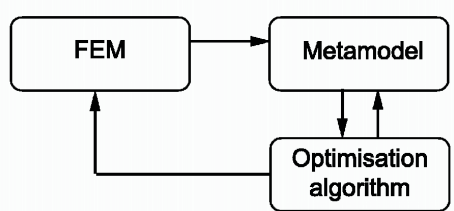

(b)

Fig. 17. (a): Direct optimization. (b): Approximate optimization.

The fourth group is the so-called adaptive algorithms. Adaptive algorithms are not coupled to $\mathrm{FE}$ in the same way as the other three groups of algorithms. Adaptive algorithms are incorporated within the FE code and generally optimize the time dependent load paths of the metal forming process during each increment of the FE calculation. An advantage is that the optimum is obtained in only one FE simulation. However, access to the source code of the FE software is necessary and only time dependent design variables can be taken into account. These disadvantages seriously limit the general applicability of these kinds of algorithms. Literature describes several applications of these algorithms to metal forming [41,42,48,50-55,59,60,78], especially to optimize the internal pressure and axial feeding load paths in hydroforming.

All groups of optimization algorithms introduced in this section have been applied to all kinds of optimization problems in metal forming. In general, one can conclude from literature that specific problems for specific metal forming processes are - sometimes quite arbitrarily - modeled, and subsequently solved using an algorithm suitable for that specific application. However, a generally applicable optimization strategy for modeling and solving optimization problems in metal forming problems is lacking. Therefore, an optimization strategy is developed here which can be applied to model and solve all kinds of optimization problems for all kinds of metal forming processes using any simulation code. 


\subsection{Optimization Strategy for Metal Forming Processes}

The proposed optimization strategy is published in detail in [83]. This section contains a summary of the strategy which comprises three stages. In the first stage the optimization problem is modeled (Section 4.2.1). Then the most important design variables are determined by screening in stage 2 (Section 4.2.2). The last stage comprises the actual solving of the optimization problem (Section 4.2.3).

\subsubsection{Modeling}

The first stage is to model the optimization problem. The challenge is to design a structured methodology that is on the one hand generally applicable to any kind of metal forming problem, but on the other hand yields a specific mathematical formulation of the optimization problem.

After collecting a large number of industrially relevant objectives, constraints and design variables, and after structuring this data using the Product Development Cycle [84], the following 7 step methodology is developed:

(i) determine the appropriate optimization stage;

(ii) select only the necessary responses;

(iii) select one response as objective function, the others as implicit constraints;

(iv) quantify the objective function and implicit constraints;

(v) select possible design variables;

(vi) define the ranges on the design variables;

(vii) identify explicit constraints.

The proposed methodology is demonstrated in Section 4.3 when it is applied to a simple hydroforming example.

\subsubsection{Screening}

The modeling stage yields a specific optimization model. However, many design variables may be present, which makes the problem time consuming to solve. It is worthwhile to invest some time in reducing the number of design variables before applying the optimization algorithm. This is done in the screening stage.

The importance of the design variables is screened by applying a Design Of Experiments (DOE) plan. Applying DOE, one selects a couple of combinations of the design variables at which one would like to evaluate the responses (objective function and implicit constraint values in case of optimization).
These response measurements can subsequently be used to estimate the effect of the design variables on the responses [80]. The variables with the largest effects may be kept in the optimization model whereas the variables having less effect may be omitted. In such a way, the number of design variables may be significantly decreased while maintaining control over objective function and constraints during optimization.

The amount and direction of the effect of each variable on each response can be nicely displayed in Pareto and Effect plots. An example of a Pareto plot is presented in Figure 18. The bars in the Pareto plot show the effect of a parameter (e.g. $R$ ) on the objective function, the solid line shows the cumulative effect.

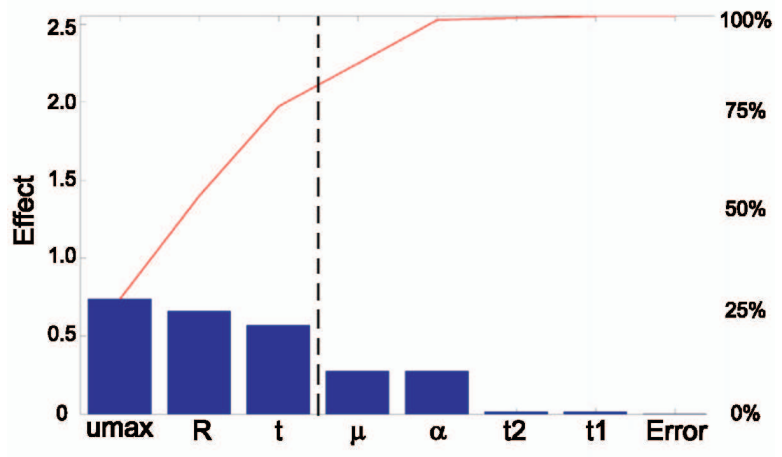

Fig. 18. A Pareto plot.

\subsubsection{Solving}

The final stage of the optimization strategy is to solve the optimization problem by a suitable algorithm. Based on the literature study presented in Section 4.1, use of an approximate optimization algorithm is proposed: it is efficient since several calculations can be run at the same time on parallel processors and it converges to the global optimum which mostly results in better results than local algorithms. The disadvantage that this type of algorithms is not efficient in case many design variables are present is overcome by the screening stage of the optimization strategy. Additionally, the algorithm is generally applicable to all kinds of metal forming processes, products and problems since the FE simulations are included as a black-box.

Details on the developed specific algorithm have been presented in several publications [85-87]. An overview of the algorithm is presented in Figure 19. The algorithm allows for sequential improvement of 
the accuracy and can thus be denoted as a Sequential Approximate Optimization (SAO) algorithm.

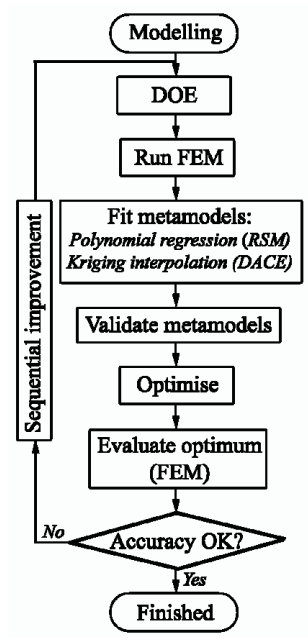

Fig. 19. Sequential Approximate Optimization [83,85-87].

The efficiency of the algorithm has been assessed by applying this and other optimization algorithms to two forging processes, see $[88,89]$.

\subsection{Application to Hydroforming}

The proposed optimization strategy - and the potential of optimization in general - is demonstrated by applying it to a simple hydroforming example, shown in Figure 20.

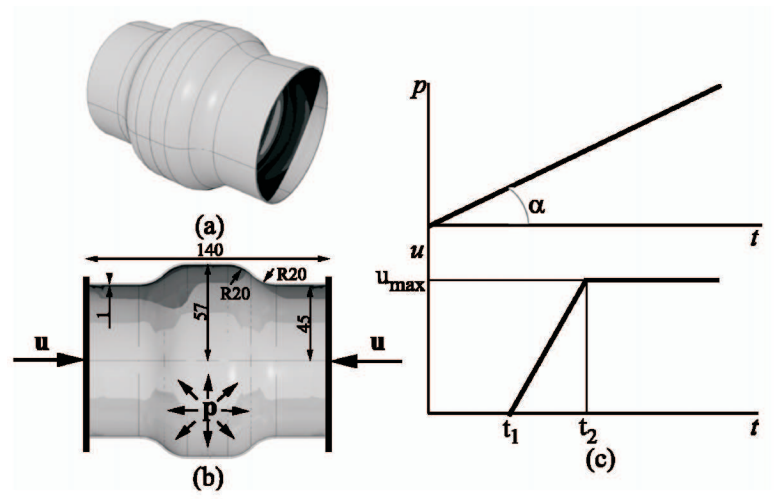

Fig. 20. (a) A simple hydroformed product; (b) Dimensions; (c) Typical load paths for hydroforming.

\subsubsection{Modeling}

The proposed 7 step methodology is followed to model the optimization problem: (i) determine the appropriate optimization stage: aim of optimization is to design the manufacturing process in order to produce the part presented in Figure 20(a);

(ii) select only the necessary responses: essential product properties are the wall thickness distribution and the outer shape accuracy of the part;

(iii) select one response as objective function, the others as implicit constraints: the uniform wall thickness distribution is the objective, the constraint is the outer shape which has been formulated as the distance between the final product and the die;

(iv) quantify the objective function and implicit constraints: final quantification of the responses is based on several properties of the responses and is performed by a table proposed in [83];

(v) select possible design variables: in this case the Process Variables (PV's) are possible design variables. Amongst others, PV's can be categorized in (see [83]):

- geometrical PV's: the initial tube radius and thickness;

- load path PV's: the typical internal pressure and axial feeding load paths for hydroforming are presented in Figure 20(c) and can be described by four design variables. Another process parameter taken into account is the friction between product and die;

- material PV's: no design variables are taken into account from this category.

(vi) define the ranges on the design variables: upper and lower bounds have been defined on all design variables;

(vii) identify explicit constraints: explicit constraints are defined by impossible combinations of the design variables. The fact that the time when axial feeding stops should be larger than the time when it starts generates an explicit constraint. Another explicit constraint has been defined based on the convergence behavior of the FE calculations for certain combinations of the load path parameters.

The 7 step methodology yields a mathematically formulated optimization model with a total of 7 design variables for this example. For a detailed description of the mathematical model, the reader is referred to [83]. 


\subsubsection{Screening}

A total of 7 design variables is not that many, hence it is possible to apply the Sequential Approximate Optimization algorithm immediately. However, for demonstration purposes, a screening step of 8 calculations is performed. The resulting Pareto plot for the objective function is presented in Figure 18. Based on this plot, one may estimate that keeping $u_{\max }, R$ and $t$, and omitting the other four variables will still result in about $80 \%$ control over the objective function. A similar Pareto plot can be generated for the implicit constraint. $u_{\max }$, $t_{1}$ and $t_{2}$ were the most important variables for the filling of the die. Now, the number of design variables is reduced to 5 variables only.

\subsubsection{Solving}

The Sequential Approximate Optimization (SAO) algorithm has been applied to the reduced optimization problem. Figure 21 shows the convergence behavior of the algorithm. The simulations have been performed on 16 parallel processors, hence the total calculation time was much shorter than running the 110 simulations sequentially.

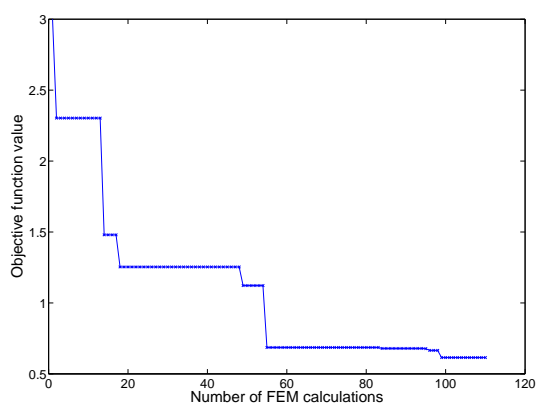

Fig. 21. Convergence of the optimization algorithm.

The optimized values of the design variables are displayed in Table 1. The optimal objective function value $f$ is 0.615 . Note the optimal initial tube thickness of $1.11 \mathrm{~mm}$. Considering the perfect wall thickness of $1 \mathrm{~mm}$ and material thinning due to inflation of the tube, this slightly thicker initial tube thickness is indeed the result one would intuitively expect to be optimal.

Table 1

\begin{tabular}{|c|c|c|c|c|c|c|c|}
\hline$t_{1}$ & $t_{2}$ & $\alpha$ & $u_{\max }$ & $R$ & $t$ & $\mu$ & $f$ \\
\hline 1.97 & 2.50 & 12 & 4.33 & 42.32 & 1.11 & 0.15 & 0.615 \\
\hline
\end{tabular}

Optimized process settings, see also Figure 20.
Figure 22 presents the wall thickness distribution throughout the final product for the perfect product (uniform wall thickness of $1 \mathrm{~mm}$ ), some arbitrary settings of the design variables (the 8 screening calculations) and the optimized process. The optimized process yields a significantly better product, which demonstrates the high potential of optimization in metal forming in general and specifically the optimization strategy proposed in Section 4.2.

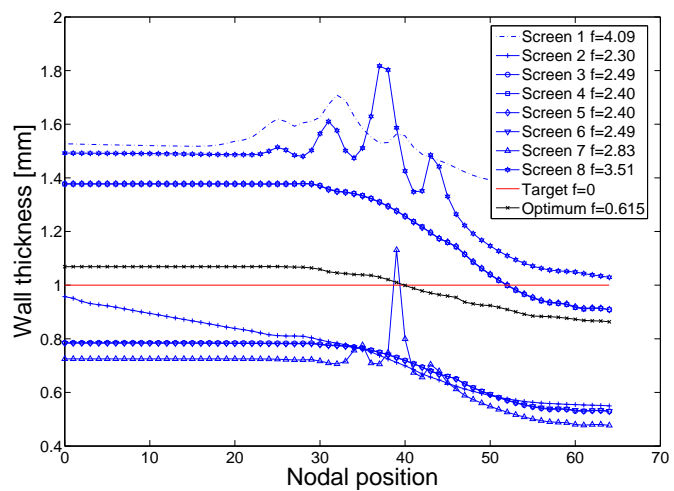

Fig. 22. Wall thickness distribution.

\section{Discussion and Future Trends}

The accuracy of today's springback predictions does not meet the industrial requirements, leading to a time and cost consuming experimental and numerical trial and error process. The accuracy can be improved by developing guidelines and sophisticated algorithms to accurately predict springback. In this article, guidelines are given for the mesh size and the potential of a through-thickness adaptive integration scheme is shown. Using this new integration scheme assures accurate results at minimal computational costs.

Now that the accuracy of the springback prediction is improved, the FE simulation can be used to adapt the geometry of the forming tools and the process parameters to compensate for springback. Two springback compensation algorithms were discussed, the Smooth Displacement Adjustment (SDA) method and the iterative SDA method. The iterative compensation algorithm is favorable since an overcompensation factor is not required. Besides it is shown that in general the overcompensation factor varies over the product, making a compensation method with a fixed overcompensation factor less useable. Finally, a tool is developed to modify 
the CAD tool geometry automatically, based on the compensation algorithm. The principle of this algorithm is proved to be valid; however, more research in this field is necessary to make this tool industrially applicable.

The combination of mathematical optimization techniques with FE simulations in itself is perhaps the most important trend in advanced materials processing. Two decades ago, metal forming was solely performed by an experimental trial-and-error process. The development of FE codes for metal forming process moved this trial-and-error process from the factory to the computer, which implied a significant decrease of development time and costs. It is foreseen that the next major step in metal forming is the development of optimization techniques to really design optimal (cheaper, better, more robust, etc) processes and products instead of just feasible ones.

Some trends can also be observed within the field of optimization of metal forming. Extensive experience has been gained concerning suitable optimization algorithms. The trend is towards global algorithms rather than local algorithms: global algorithms yield larger improvements than local ones. A major challenge is to limit the total calculation time for these algorithms, since they generally require more time consuming FE simulations than local algorithms. The increase in computer power and the simultaneous decrease of prices of processors, however, has moved many industries to purchase clusters with many parallel processors, which makes the application of global algorithms possible today. With respect to global optimization algorithms, the trend is to focus on making genetic/evolutionary algorithms more efficient and/or making approximate optimization algorithm more accurate by further developing metamodeling techniques.

Many available algorithms are already sufficiently good to solve optimization problems in metal forming. However, more emphasis should be on modeling optimization problems. With the proposed optimization strategy a first attempt is made, but the proposed modeling methodology is by no means the only possible solution. A significant increase in attention for optimization modeling will give insight in the phenomena influencing metal forming processes, their FE models, and the optimization problem the optimization algorithms have to deal with. This will contribute more to optimizing metal forming processes than developing just another slightly more efficient algorithm.
A final trend is related to a very important item in mass production: robustness. A major improvement would be to develop optimization strategies that include noise variables such as material noise in addition to design variables only. These "robust optimization" techniques are expected to significantly contribute to the design of robust and reliable production processes with as a consequence a lower scrap rate, lower production costs and high quality products. More details on optimizing for robust processes can be found in [90]

Acknowledgements Most of the research has been carried out under projects in the framework of the Netherlands Institute for Metals Research (NIMR). The industrial partners co-operating in this project are gratefully acknowledged for their useful contributions to this research.

\section{References}

[1] R. M. Cleveland, A. K. Ghosh, Inelastic effects on springback in metals, International Journal of Plasticity 18 (5-6) (2002) 769-785.

[2] K. Li, W. Carden, R. Wagoner, Simulation of springback, International Journal of Mechanical Sciences 44 (1) (2002) 103-122.

[3] T. Meinders, A. Konter, S. Meijers, E. Atzema, H. Kappert, A sensitivity analysis on the springback behaviour of the unconstrained bending problem, International Journal of Forming Processes .

[4] D.-W. Park, S.-I. Oh, A four-node shell element with enhanced bending performance for springback analysis, Computer Methods in Applied Mechanics and Engineering 193 (23-26) (2004) 2105-2138.

[5] J. Li, L. Geng, R. Wagoner, Simulation of springback: Choice of element, in: M. Geiger (Ed.), Proceedings of Advanced Technology of Plasticity, Vol. 3, SpringerVerlag, Nuremberg, Germany, 1999, pp. $2091-2099$.

[6] Numisheet benchmark, in: A. Makinouchi, et.al. (Eds.), Proceedings of NUMISHEET, Isehara, Japan, 1993.

[7] W.-R. Harn, T. Belytschko, Adaptive multi-point quadrature for elastic-plastic shell elements, Finite Elements in Analysis and Design 30 (4) (1998) 253.

[8] R. H. Wagoner, M. Li, Advances in springback, in: L. Smith, F. Pourboghrat, J. Yoon, T. Stoughton (Eds.), Proceedings of NUMISHEET, Vol. Part A, Detroit, MI, U.S.A., 2005, pp. 209-214.

[9] R. J. Rice, A metalgorithm for adaptive quadrature, Journal of the ACM (JACM) 22 (1) (1975) 61-82.

[10] H. Armen, A. Pifko, H. Levine, Finite element analysis of structures in the plastic range, Contractor report NASA CR-1649, Grumman Aerospace Corporation (1971).

[11] P. Davis, P. Rabinowitz, Methods of numerical integration, 2nd Edition, Academic Press, Inc., 1985. 
[12] L. Smith, Chapter 5, springback compensation, in: L. Smith, et.al. (Eds.), Proceedings of NUMISHEET, AIP.

[13] W. Gan, R. H. Wagoner, Die design method for sheet springback, International Journal of Mechanical Science 46 (2004) 1097-1113.

[14] W. Gan, R. Wagoner, K. Mao, S. Price, F. Rasouli, Practical design methods using fe modeling applied to sheet parts and dies, Journal of Material Processing and Technology 126 (2004) 360-367.

[15] R. Wagoner, Fundamental aspects of springback in sheet metal forming, in: V. Brucato (Ed.), proceedings of ESAFORM, 2003, pp. 7-14.

[16] R. Lingbeek, T. Meinders, S. Ohnimus, M. Petzoldt, J.Weiher, Springback compensation: Fundamental topics and practical application, in: N. Juster, A. Rosochowski (Eds.), Proceedings of ESAFORM, 2006, pp. 403-406.

[17] R. Lingbeek, H. Huétink, S. Ohnimus, M. Petzoldt, J. Weiher, The development of a finite elements based springback compensation tool for sheet metal products, Journal of Materials Processing and Technology 169 (2005) 115-125.

[18] R. Lingbeek, F. van Houten, Modification of trimmed and imperfect surfaces while retaining smooth surface transitions, submitted to CAD (2006).

[19] P. Papalambros, D. Wilde, Principles of optimal design, Cambridge University Press, New York, USA, 2000, iSBN 0-521-62727.

[20] J. Cao, S. Li, Z. Xia, S. Tang, Analysis of an axisymmetric deep-drawn part forming using reduced forming steps, Journal of Materials Processing Technology 117 (1-2) (2001) 193-200.

[21] K. Debray, Z. Sun, R. Radjai, Y. Guo, L. Dai, Y. Gu, Optimum design of addendum surfaces in sheet metal forming process, in: Proceedings of NUMIFORM, Columbus OH, USA, 2004.

[22] N. Kim, K. Choi, J. Chen, Die shape design optimization of sheet metal stamping process using meshfree method, International Journal for Numerical Methods in Engineering 51 (2001) 1385-1405.

[23] J. Kleinermann, Identification paramétrique et optimisation des procédés de mise à forme par problèmes inverses, Ph.D. thesis, Université de Liège, Liège, Belgium, in French (2001).

[24] J. Kleinermann, J. Ponthot, Parameter identification and shape/process optimization in metal forming simulation, Journal of Materials Processing Technology 139 (1-3) (2003) 521-526.

[25] J. Ponthot, J. Kleinermann, Optimisation methods for initial/tool shape optimisation in metal forming processes, International Journal of Vehicle Design 39 (12) (2005) 14-24.

[26] H. Naceur, Y. Guo, J. Batoz, C. Knopf-Lenoir, Optimization of drawbead restraining forces and drawbead design in sheet metal forming process, International Journal of Mechanical Sciences 43 (10) (2001) 2407-2434.

[27] H. Naceur, A. Delamézière, J. Batoz, Y. Guo, C. KnopfLenoir, Optimization of drawbead restraining forces and drawbead design in sheet metal forming process, Journal of Materials Processing Technology 146 (2004) 250-262.
[28] Z. Lin, X. Juchen, W. Xinyun, H. Guoan, Sensitivity based optimization of sheet metal forming tools, Journal of Materials Processing Technology 124 (3) (2002) 319328.

[29] X. Shi, J. Chen, Y. Peng, X. Ruan, A new approach of die shape optimization for sheet metal forming processes, Journal of Materials Processing Technology 152 (2004) 35-42.

[30] L. Ben Ayed, A. Delamézière, J. Batoz, C. Knopf-Lenoir, Optimization and control of the blankholder force in sheet metal stamping with application to deep drawing of a cylindrical cup, in: Proceedings of ECCOMAS, Jyväskylä, Finland, 2004.

[31] L. Ben Ayed, A. Delamézière, J. Batoz, C. Knopf-Lenoir, Optimization of the blankholder force with application to the numisheet'02 deep drawing benchmark test b1, in: Proceedings of NUMIFORM, Columbus OH, USA, 2004.

[32] L. Ben Ayed, A. Delamézière, J. Batoz, C. Knopf-Lenoir, Optimization of the blankholder force distribution in deep drawing, in: Proceedings of APOMAT, Morschach, Switzerland, 2005.

[33] P. Breitkopf, H. Naceur, A. Rassineux, P. Villon, Moving least squares response surface approximation: Formulation and metal forming applications, Computers and Structures 83 (17-18) (2005) 1411-1428.

[34] H. Naceur, P. Breitkopf, C. Knopf-Lenoir, A. Rassineux, P. Villon, Response surface methods for the optimal design of the initial blank in sheet metal forming process, in: Proceedings of ESAFORM, Salerno, Italy, 2003.

[35] T. Jansson, Optimization of sheet metal forming processes, Licentiate thesis, Universitet Linköping, Linköping, Sweden (2002).

[36] T. Jansson, A. Andersson, L. Nilsson, Optimization of draw-in for an automotive sheet metal part - an evaluation using surrogate models and response surfaces, Journal of Materials Processing Technology 159 (2005) 426-234.

[37] H. Lenoir, N. Boudeau, An optimization procedure for springback compensation, in: Proceedings of ESAFORM, Salerno, Italy, 2003.

[38] K. Liew, H. Tan, T. Ray, M. Tan, Optimal process design of sheet metal forming for minimum springback via an integrated neural network evolutionary algorithm, Structural and Multidisciplinary Optimization 26 (2004) 284-294.

[39] H. Naceur, S. Ben-Elechi, C. Knopf-Lenoir, J. Batoz, Response surface methodology for the design of sheet metal forming parameters to control springback effects using the inverse approach, in: Proceedings of NUMIFORM, Columbus OH, USA, 2004.

[40] H. Naceur, S. Ben-Elechi, J. Batoz, The inverse approach for the design of sheet metal forming parameters to control springback effects, in: Proceedings of ECCOMAS, Jyväskylä, Finland, 2004.

[41] Z. Sheng, S. Jirathearanat, T. Altan, Adaptive FEM simulation for prediction of variable blank holder force in conical cup drawing, International Journal of Machine Tools and Manufacture 44 (2004) 487-494.

[42] M. Strano, L. Carrino, Adaptive selection of loads during FEM simulation of sheet forming processes, in: Proceedings of NUMIFORM, Columbus OH, USA, 2004. 
[43] O. Schenk, M. Hillmann, Optimal design of metal forming die surfaces with evolution strategies, Computers and Structures 82 (2004) 1695-1705.

[44] B. Endelt, Least square optimization techniques applied on sheet metal forming, Ph.D. thesis, Aalborg University, Aalborg, Denmark (2003).

[45] B. Endelt, K. Nielsen, Least-square formulation of the object function, applied on hydro mechanical tube forming, in: Proceedings of SheMet, 2001.

[46] K. Fann, P. Hsiao, Optimization of loading conditions for tube hydroforming, Journal of Materials Processing Technology 140 (1-3) (2003) 520-524.

[47] S. Jirathearanat, T. Altan, Optimization of loading paths for tube hydroforming, in: Proceedings of NUMIFORM, Columbus OH, USA, 2004.

[48] W. Sillekens, R. Werkhoven, Hydroforming processes for tubular parts: Optimisation by means of adaptive and iterative FEM simulation, International Journal of Forming Processes 4 (3-4) (2001) 377-393.

[49] J. Yang, B. Jeon, S. Oh, Design sensitivity analysis and optimization of the hydroforming process, Journal of Materials Processing Technology 113 (2001) 666-672.

[50] C. Labergère, J. Gelin, Comparison between optimization and control strategies to determine command laws in hydroforming processes, in: Proceedings of ESAFORM, Trondheim, Norway, 2004.

[51] C. Labergère, J. Gelin, New strategies for optimal control of command laws for tube hydroforming processes, in: Proceedings of NUMIFORM, Columbus, OH, USA, 2004.

[52] A. Aydemir, J. de Vree, W. Brekelmans, M. Geers, W. Sillekens, R. Werkhoven, An adaptive simulation approach design for tube hydroforming processes, Journal of Materials Processing Technology 159 (2005) 303-310.

[53] R. Di Lorenzo, L. Filice, D. Umbrello, F. Micari, An integrated approach to the design of tube hydroforming processes: artificial intelligence, numerical analysis and experimental investigation, in: Proceedings of NUMIFORM, Columbus OH, USA, 2004.

[54] K. Johnson, B. Nguyen, R. Dawies, G. Grant, M. Khaleel, A numerical process control method for circular-tube hydroforming prediction, International Journal of Plasticity 20 (2004) 1111-1137.

[55] P. Ray, B. Mac Donald, Determination of the optimal load path for tube hydroforming processes using a fuzzy load control algorithm and finite element analysis, Finite Elements in Analysis and Design 41 (2004) 173-192.

[56] N. Abedrabbo, N. Zafar, R. Averill, F. Pourboghrat, R. Sidhu, Optimization of a tube hydroforming process, in: Proceedings of NUMIFORM, Columbus OH, USA, 2004.

[57] R. Weyler, L. Neamtu, G. Duffett, An approach to the computer simulation of metal forming processes, in: Proceedings of ECCOMAS, Jyväskylä, Finland, 2004.

[58] Y. Kim, J. Lee, S. Hong, Optimal design of superplastic forming processes, Journal of Materials Processing Technology 112 (2-3) (2001) 166-173.

[59] L. Carrino, G. Giuliano, C. Palmieri, On the optimisation of superplastic forming processes by the finite-element method, Journal of Materials Processing Technology 143-144 (1) (2003) 373-377.
[60] L. Carrino, G. Giuliano, G. Napolitano, A posteriori optimisation of the forming pressure in superplastic forming processes by the finite element method, Finite Elements in Analysis and Design 39 (2003) 1083-1093.

[61] S. Byon, S. Hwang, FEM-based process optimal design in steady-state metal forming considering strainhardening, Computers and Structures 79 (14) (2001) 1363-1375.

[62] Z. Lin, X. Juchen, W. Xinyun, H. Guoan, Optimization of die profile for improving die life in the hot extrusion process, Journal of Materials Processing Technology 142 (3) (2003) 659-664.

[63] X. Duan, T. Sheppard, Shape optimisation using FEA software: A V-shaped anvil as an example, Journal of Materials Processing Technology 120 (1-3) (2002) 426431.

[64] G. Zhao, X. Ma, X. Zhao, R. Grandhi, Studies on optimization of metal forming processes using sensitivity analysis methods, Journal of Materials Processing Technology 147 (2004) 217-228.

[65] J. Repalle, R. Grandhi, Optimum design of forging process parameters and preform shape under uncertainties, in: Proceedings of NUMIFORM, Columbus OH, USA, 2004.

[66] N. Thiyagarajan, R. Grandhi, 3-D preform shape optimization in metal forming, in: Proceedings of NUMIFORM, Columbus OH, USA, 2004.

[67] M. Poursina, C. António, J. Parvizian, L. Sousa, C. Castro, Eliminating folding defect in forging parts using a genetic algorithm, in: Proceedings of ESAFORM, Salerno, Italy, 2003.

[68] T. Do, L. Fourment, M. Laroussi, Sensitivity analysis and optimization algorithms for 3D forging process design, in: Proceedings of NUMIFORM, Columbus OH, USA, 2004.

[69] L. Fourment, T. Do, A. Habbal, M. Bouzaiane, Gradient, non-gradient and hybrid algorithms for optimizing $2 \mathrm{D}$ and $3 \mathrm{D}$ forging sequences, in: Proceedings of ESAFORM, Cluj-Napoca, Romania, 2005.

[70] L. Fourment, T. Do, A. Habbal, M. Bouzaiane, Optimization of forging sequences using gradient, nongradient and hybrid algorithms, in: Proceedings of APOMAT, Morschach, Switzerland, 2005.

[71] C. António, C. Castro, L. Sousa, Optimization of metal forming processes, Computers and Structures 82 (2004) 1425-1433.

[72] C. Castro, C. António, L. Sousa, Optimisation of shape and process parameters in metal forging using genetic algorithms, International Journal of Materials Processing Technology 146 (2004) 356-364.

[73] L. Sousa, C. António, C. Castro, Optimisation of multi-step hot forging operations, in: Proceedings of ESAFORM, Salerno, Italy, 2003.

[74] H. Palaniswamy, G. Ngaile, T. Altan, Optimization of blank dimensions to reduce springback in the flexforming process, Journal of Materials Processing Technology 146 (2004) 28-34.

[75] A. Sahai, U. Schramm, T. Buranathiti, W. Chen, J. Cao, C. Xia, Sequential optimization and reliability assessment method for metal forming processes, in: Proceedings of NUMIFORM, Columbus OH, USA, 2004.

[76] T. Ohata, Y. Nakamura, T. Katayama, E. Nakamachi, Development of optimum process design system for 
sheet fabrication using response surface method, Journal of Materials Processing Technology 143-144 (1) (2003) $667-672$.

[77] P. Breitkopf, H. Naceur, A. Rassineux, P. Villon, Optimizing metal forming processes using response surface approximation and inverse approach surrogate model, in: Proceedings of ESAFORM, Trondheim, Norway, 2004.

[78] C. Labergère, A. Lejeune, J. Gelin, Control of damage in flanges hydroforming, in: Proceedings of ECCOMAS, Jyväskylä, Finland, 2004.

[79] M.

Emmerich, A. Giotis, M. Özdemir, T. Bäck, K. Giannakoglou, Metamodel-assisted evolution strategies, in: Proceedings of the International Conference on Parallel Problem Solving from Nature, 2002.

[80] R. Myers, D. Montgomery, Response Surface Methodology: Process and Product Optimization Using Designed Experiments, $2^{\text {nd }}$ Edition, John Wiley and Sons, Inc., New York, USA, 2002, iSBN 0-471-41255-4.

[81] M. Koc, T. Allen, S. Jiratheranat, T. Altan, Use of FEA and design of experiments to establish design guidelines for simple hydroformed parts, International Journal of Machine Tools and Manufacture 40 (15) (2000) 22492266.

[82] A. Revuelta, J. Larkiola, Applying neural networks in the final thickness optimisation of a thin hydroformed part, in: Proceedings of ECCOMAS, Jyväskylä, Finland, 2004 .

[83] M. Bonte, A. van den Boogaard, J. Huétink, An optimisation strategy for industrial metal forming processes, submitted (2006).

[84] K. Yang, B. El-Haik, Design For Six Sigma; A roadmap for Product Development, McGraw-Hill, Inc., New York, USA, 2003.

[85] M. Bonte, A. van den Boogaard, J. Huétink, Metamodelling techniques for the optimisation of metal forming processes, in: Proceedings of ESAFORM, ClujNapoca, Romania, 2005, pp. 155-158.

[86] M. Bonte, A. van den Boogaard, J. Huétink, Solving optimisation problems in metal forming using finite element simulation and metamodelling techniques, in: Proceedings of APOMAT, Morschach, Switzerland, 2005, pp. 242-251.

[87] M. Bonte, A. van den Boogaard, J. Huétink, A metamodel based optimisation algorithm for metal forming processes, accepted (2006).

[88] M. Bonte, T. Do, L. Fourment, A. van den Boogaard, J. Huétink, A. Habbal, A comparison of optimisation algorithms for metal forming processes, in: N. Juster, A. Rosochowski (Eds.), Proceedings of ESAFORM, Glasgow, UK, 2006, pp. 883-886.

[89] M. Bonte, L. Fourment, T. Do, A. van den Boogaard, J.Huétink, Optimisation of metal forming processes using finite element simulations: A sequential approximate optimisation algorithm and its comparison to other algorithms by application to forging, submitted (2006).

[90] M. Bonte, A. van den Boogaard, B. Carleer, Optimising towards robust metal forming processes, in: N. Juster, A. Rosochowski (Eds.), Proceedings of ESAFORM, Glasgow, UK, 2006, pp. 47-50. 